\title{
Differential activation of Xenopus homeo box genes by mesoderm-inducing growth factors and retinoic acid
}

\author{
Ken W.Y. Cho and Eddy M. De Robertis ${ }^{1}$ \\ Department of Biological Chemistry, University of California, Los Angeles, California 90024-1737 USA
}

\begin{abstract}
What is the nature of positional information during embryogenesis? By using Xenopus homeo box genes as anteroposterior (A-P) markers, we confirm the findings of others that mesoderm-inducing growth factors and retinoic acid (RA) can provide positional information along the axis of the body. Xenopus tissue culturemesoderm-inducing factor (XTC-MIF) selectively activates an anteriorly expressed homeo box gene (XIHbox 1), while basic fibroblast growth factor (bFGF) activates selectively a posteriorly expressed homeo box gene (XlHbox 6). RA activates expression of the posterior gene XlHbox 6, but not of XlHbox 1. This activation, however, requires exposure to growth factors. The data suggest that growth factors and RA may cooperate with each other to provide positional information in vertebrates.
\end{abstract}

[Key Words: Xenopus laevis; axis formation; growth factors; retinoic acid; mesoderm induction; homeo box genes]

Received August 3, 1990; revised version accepted August 30, 1990.

In Amphibia the anteroposterior (A-P) axis arises through a series of inductive events, as demonstrated by Spemann's organizer experiment (for review, see Spemann 1938). Induction starts early in embryogenesis, with blastula endodermic cells releasing signals that instruct neighboring cells to become mesoderm (Nieuwkoop 1969). Recently, Ruiz i Altaba and Melton (1989b) have shown that Xenopus tissue culture-mesoderm-inducing factor (XTC-MIF), a molecule now known to be identical to the transforming growth factor- $\beta$ (TGF- $\beta$ )like growth factor activin (Smith et al. 1990), induces anterodorsal structures, whereas basic fibroblast growth factor (bFGF) induces posteroventral structures. This raised the possibility that peptide growth factors may provide A-P positional information (Ruiz i Altaba and Melton 1989b), in addition to their previously known role in the formation of dorsal and ventral structures (Slack et al. 1987; Smith 1987; Green et al. 1990).

Another candidate molecule for providing positional information is retinoic acid (RA). It has been shown that Xenopus embryos treated with RA at gastrulation become posteriorized and deficient in head structures (Durston et al. 1989; Sive et al. 1990). RA is also known to produce mirror image duplication of posterior digits in the chick wing bud (Tickle et al. 1982). A gradient of RA, with a maximum at the posterior end, is present in the wing bud (Thaller and Eichele 1987). The mechanism of RA action probably differs from the mechanism of growth factor induction because the former is me-

'Corresponding author. diated by a nuclear receptor and the latter would be mediated by a plasma membrane receptor.

Vertebrate homeo box genes provide good markers for A-P axis development (Dolle and Duboule 1989; Graham et al. 1989). Furthermore, in some cases they have been shown to be directly involved in the specification of the A-P body axis (Wright et al. 1989; Kessel et al. 1990|, much like their Drosophila counterparts.

A posterior homeo box gene, Xhox 3 /which has a homeo box of the even-skipped-type), has been previously used by Ruiz i Altaba and Melton (1989b) to show that bFGF preferentially induces a posterior marker in Xenopus animal cap explants. The first homeo box gene reported to be activated by mesoderm induction was $M i x-1$, a Xenopus gene that is highly diverged from the Antennapedia class and whose role in axis formation is not known at present (Rosa 1989). Mix-1 is activated by XTC-MIF. These observations prompted us to investigate the mechanism of transcriptional activation of XlHbox 1 and XlHbox 6, which are Xenopus genes belonging to the Antennapedia-type Hox gene complexes present in vertebrates (De Robertis et al. 1990).

XlHbox 1 is a homeo box gene of the Antennapediatype expressed in the anterior trunk region of the embryo (De Robertis et al. 1989), and it is thought to be directly involved in the specification of A-P regional identity (Wright et al. 1989). XlHbox 1 is expressed as a narrow band across the cervical region of the central nervous system, neural crest, and mesoderm. Its transcription is controlled by two promoters, PR I and PR II, 
that differentially utilize the same reading frame to produce a short and long homeo domain protein /Cho et al. 1988). Here we show that $\mathrm{XlHbox} 1$ is preferentially activated by XTC-MIF. XlHbox 6 has a homeo box of the $A b d o m i n a l-B$ type and is expressed in the posterior region of the embryo (Sharpe et al. 1987; Wright et al. 1990). We find that this gene is preferentially activated by $\mathrm{bFGF}$, in agreement with previous findings for the posterior gene Xhox 3 (Ruiz i Altaba and Melton 1989b). Furthermore, RA is able to increase strongly steady-state levels of XlHbox 6 mRNA, but only in cooperation with growth factors.

\section{Results}

Activation of an anteriorly expressed homeo box gene by XTC-MIF

To determine whether activation of the Antennapediatype homeo box gene XlHbox 1 (Fig. 1) requires mesoderm induction, we initially performed animal-vegetal (A/V) conjugates (Fig. 2A). In isolation, animal cap cells give rise to skin ectoderm, while vegetal cells remain as undifferentiated endoderm. When combined with each other, however, mesoderm is induced by factors released from the endoderm cells (Nieuwkoop 1969). Figure 2B shows RNase protection assays demonstrating that $X 1 H$ box 1 transcripts are absent in either fragment cultured alone (A or $\mathrm{V}$ ), but are induced in $\mathrm{A} / \mathrm{V}$ conjugates. Both promoters of XlHbox 1 (PR I and PR II) are similarly activated in A/V conjugates (Fig. 2B). These results suggest that transcription of $X I H b o x 1$ requires mesoderm induction.

Although the exact nature of the mesoderm-inducing molecules released by endoderm is not known, recent studies strongly suggest that growth factors are involved in this process. bFGF added to animal caps induces posteroventral mesoderm (Slack et al. 1987; Ruiz i Altaba and Melton 1989b; Green et al. 1990), and the frog blastula contains both bFGF mRNA and protein (Kimelman and Kirschner 1987). XTC-MIF is a $27-\mathrm{kD}$ protein that is the TGF- $\beta$-related growth factor activin (Smith et al. $1990)$ and is the most potent known inducer of anterodorsal mesoderm (Smith 1987; Ruiz i Altaba and Melton 1989b; Green et al. 1990). Xenopus eggs contain a TGF- $\beta$-related maternal mRNA called $\mathrm{Vg} 1$, which is specifically localized to the vegetal pole (Weeks and Melton 1987). Therefore, animal caps were incubated with either XTC-MIF or bFGF, and the activation of the endogenous XlHbox 1 transcripts was assayed after various time intervals.

Figure 3 shows that XTC-MIF is a much better inducer of the XlHbox 1 transcripts (PR I and PR II) than bFGF. One could argue, however, that this result is due to XTC-MIF being a stronger mesoderm inducer than bFGF. To eliminate this possibility, growth factors were tested at different concentrations. The results shown in Figure 3 are for fully induced animal caps; increasing the concentration of growth factor has no further effect on homeo box gene transcription. Figure 4 shows the induction of XlHbox 1 promoters and mesodermic $\alpha$-actin
A

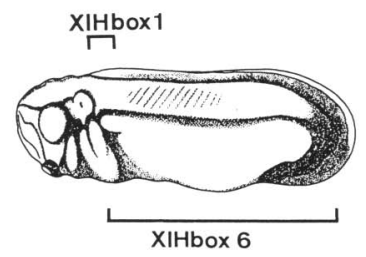

B

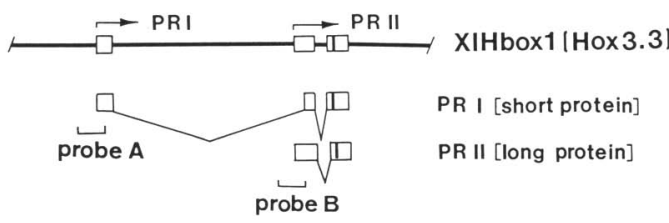

C

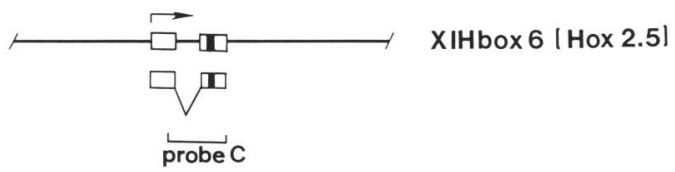

Figure 1. The homeo box gene probes used in this study. $(A)$ Schematic diagram of expression patterns of Xenopus homeo box proteins is shown. Both XlHbox 1 and XlHbox 6 proteins are expressed in central nervous system and lateral plate mesoderm. XlHbox 1 protein is expressed as a narrow band across the anterior trunk region (De Robertis et al. 1989). XlHbox 6 protein is expressed in posterior trunk region (Wright et al. 1990). ( $B$ and $C$ ) Description of homeo box gene probes used for RNase protection assays. Genomic structures of the XlHbox 1 and XlHbox 6 genes are shown. The gene is represented as a line, and exons are indicated by boxes. Two promoters, PR I and PR II, indicated by arrows above the genomic map, utilize the same open reading frame to produce short and long homeo domain proteins (Cho et al. 1988). The exons are indicated by boxes, and the homeo box is black. Probes used for RNase protection assays are indicated. Probes A and B specifically detect $X 1 H b o x 1$ PR I and PR II promoters, respectively. Probe C detects XlHbox 6 transcription.

at two growth factor concentrations. It may be noted that low concentrations of XTC-MIF that have the same degree of mesodermal $\alpha$-actin induction activity as high doses of bFGF are still better activators of XlHbox 1 expression. Thus, the difference in XlHbox 1 induction between XTC-MIF and bFGF is not due to low mesoderminducing activity of the bFGF preparation used, but rather to a differential response of XIHbox 1 to XTCMIF. We conclude that XTC-MIF and bFGF can differentially activate the XlHbox 1 gene.

\section{Activation of a posteriorly expressed homeo box gene by $b F G F$}

To test whether all homeo box genes respond in the same way to growth factors in animal caps, we tested $X 1 H b o x \quad 6$ transcripts. This gene is present at the $5^{\prime}$ end 


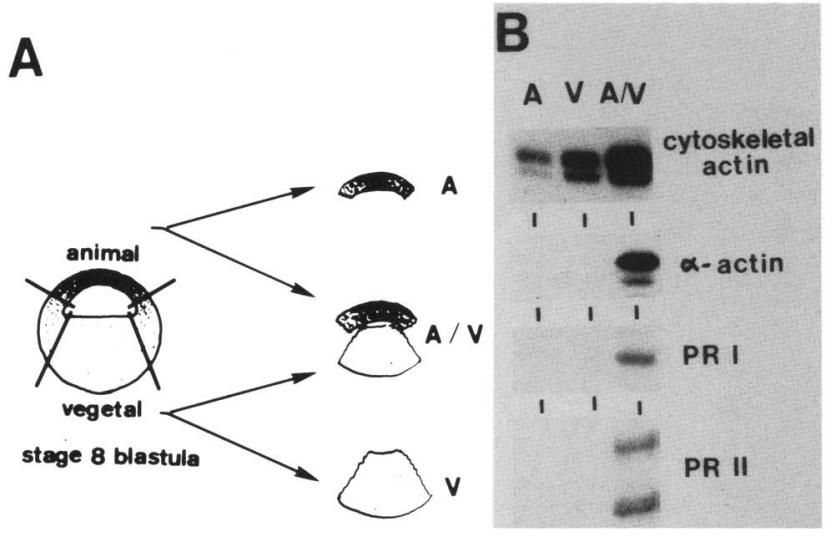

Figure 2. Mesoderm induction is required for XlHbox 1 expression. (A) Animal caps (A) and endoderm from the vegetal pole cells $(\mathrm{V})$ were isolated from stage 8 blastulae as diagramed and cultured alone or in combination (A/V). An A/V conjugate forms mesoderm. Without conjugation, animal cells remain ectodermal and vegetal cells remain endodermal. $(B)$ Stage 8 blastula embryos were dissected as described in Fig. 2A and cultured alone or in combination. After $12 \mathrm{hr}$ in culture, RNA samples were prepared and assayed by RNase protection with probes for Xenopus actin (Gurdon et al. 1985) and XlHbox 1 PR I and PR II promoters (Cho et al. 1988). Note that XlHbox 1 PR I and PR II endogenous mRNAs are not expressed in animal (A) or vegetal $(V)$ fragments when they were cultured separately but are present in the $\mathrm{A} / \mathrm{V}$ conjugates. PR II promoter of XlHbox 1 gives two protected bands because it has two transcription initiation sites, as described previously (Cho et al. 1988).

of the Xenopus Hox-2 gene complex (Fritz et al. 1989) and is expressed posteriorly in embryos (Sharpe et al. 1987; Wright et al. 1990). It is believed to be the Xenopus homolog of mammalian Hox-2.5 (Bogarad et al. 1989|, and its homeo box sequence shares similarities to that of Drosophila Abdominal-B (Wright et al. 1990).

As shown in Figure 5, XlHbox 6 stable transcripts follow the opposite behavior of those of XlHbox 1. bFGF is a potent activator of XlHbox 6, while XTC-MIF is a very poor one. In the absence of growth factors, no XlHbox 6 or XlHbox 1 transcripts were detected. We conclude that the posteriorly expressed XlHbox 6 gene is preferentially activated by bFGF.

\section{$R A$ cooperates with growth factors}

As mentioned above, treatment of Xenopus embryos with RA leads to posteriorized embryos (Durston et al. 1989; Sive et al. 1990). In cultured teratocarcinoma cell lines, most mammalian homeo box genes, including the putative XIHbox 1 and XlHbox 6 homologs (Hox-3.3 and Hox-2.5, respectively), are activated by RA (Mavilio et al. 1988). Figure 6 shows that when Xenopus embryos are treated at the gastrula stage with $10^{-6} \mathrm{M}$ RA for 30 min and then cultured until the tailbud stage, the levels of XlHbox 6 are considerably increased (sixfold, as determined by densitometry of RNase protection assays), whereas those of XIHbox 1 are unaffected. The reason for the lack of response of XlHbox $1 \mathrm{mRNA}$ to RA in intact Xenopus embryos is not known. This is in clear

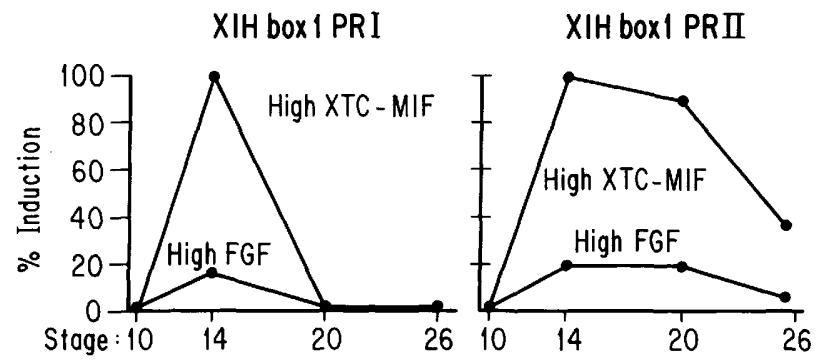

Figure 3. Anteriorly expressed XlHbox 1 homeo box gene is preferentially activated by XTC-MIF. Isolated animal caps were cultured in the presence of growth factors. RNAs were isolated when intact sibling control embryos grown in parallel reached the indicated stage of development, and analyzed by RNase protection assay using probes A and B (Fig. 1B). The levels of $X$ IHbox 1 (PR I and PR II) RNAs were normalized with respect to the amount of elongation factor $1 \alpha$ mRNA present by densitometer scanning of RNase protection autoradiographs. RNA equivalent to 20 animal caps was used for each RNase protection point. Maximal induction of each message during the course of analysis is taken as $100 \%$. Thus, $100 \%$ induction corresponds to the amount of PR I or PR II transcripts in stage 14 animal caps treated with high XTC-MIF. The maximal induction corresponds to $\sim 120 \%$ of that found in an equivalent amount of whole embryo RNA at the same stage.

contrast with its behavior in cultured cell lines (Mavilio et al. 1988). Perhaps additional cell interactions come into play in embryos that are lacking in tissue culture systems. Measurement of N-CAM transcripts (Kintner and Melton 1987) shows that the total amount of nervous tissue in these embryos is unaffected by RA treatment, suggesting that the increase in XlHbox 6 is not due to gross changes in neural induction (Fig. 6).

In animal caps, expression of XlHbox 1 was decreased or unaffected when incubated with RA, regardless of

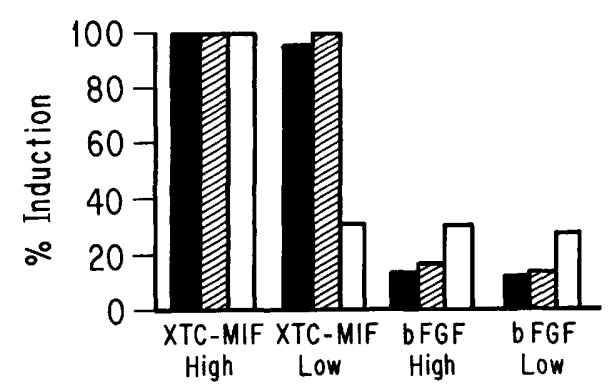

Figure 4. Induction of XlHbox 1 and mesodermic $\alpha$-actin at various growth factor concentrations. Animal caps were cultured in various concentrations of XTC-MIF and bFGF as described in Materials and methods. RNAs were isolated at stage 14 (early neurula). RNA equivalent to 20 animal caps was used for each RNase protection point, with the exception of elongation factor $1 \alpha$ samples used for normalizing RNA amounts, in which case RNA equivalent to only one animal cap was used. At low XTC-MIF concentration, the $\alpha$-actin induction level is not significantly different from that of high bFGF induction. In the histogram, maximal induction of each message (PR I, PR II, and $\alpha$-actin) at high XTC-MIF treatment is taken as $100 \%$. (口) PR I; ( $\mathbb{Q}$ ) PR II; ( $\square$ ) $\alpha$-actin. 


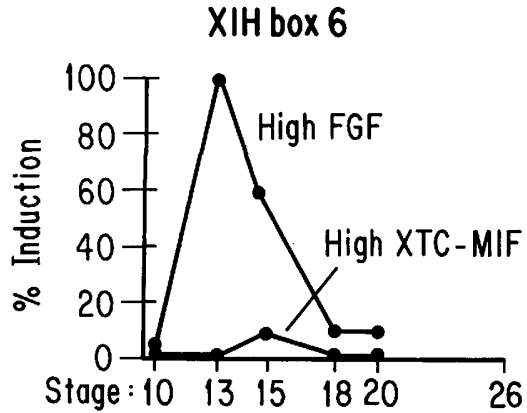

Figure 5. Posteriorly expressed XlHbox 6 homeo box gene is preferentially activated by bFGF. RNAs from growth factortreated animal caps were analyzed using XlHbox 6 antisense probe $C$ (Fig. 1C). RNA equivalent to 30 animal caps was used for each RNA protection point. An induction of $100 \%$ corresponds to the amount of transcripts in stage 13 animal caps treated with high bFGF. This maximal induction corresponds to $75 \%$ of that found in an equivalent amount of whole embryo RNA (normalized using the constitutively expressed elongation factor $1 \alpha$ probe) at the same stage.

whether XTC-MIF or bFGF was present (data not shown). However, as shown in Figure 7, RA was able to strongly potentiate $\mathrm{XlHbox} 6$ expression in combination with either growth factor. Interestingly, when animal caps were incubated with RA in the absence of growth factors, expression of XlHbox 6 was not detectable (Fig. $7 \mathrm{~A}, \mathrm{~B}$ ). Thus, RA requires growth factors to activate this homeo box gene. Figure 7 also shows that activation of XlHbox 6 mRNA by RA in the presence of growth factors was more pronounced in animal caps incubated until intact sibling control embryos grown in parallel reached stage 18 (late neurula, $19 \mathrm{hr}$ after fertilization) than in animal caps incubated until stage 15 had been reached (early to mid-neurula, $16 \mathrm{hr}$ after fertilization). These studies concerned only steady-state mRNA measurements, and therefore they do not distinguish whether RA acts at the transcriptional or post-transcriptional level.

The concentration of RA required for activation of $X 1 H b o x$ in animal caps treated with bFGF was investigated. As shown in Figure 8, half-maximal induction of $\mathrm{XlHbox} 6$ was obtained at $5 \times 10^{-7} \mathrm{M} \mathrm{RA}$, and maximal induction in the presence of bFGF was observed at $10^{-6}$ M RA. RA has no effect on the viability of animal cap cells. When animal caps were treated at various concentrations of RA $\left(10^{-5}-10^{-7} \mathrm{M}\right)$ and then sectioned and examined histologically, no detectable cell death was observed.

The results suggest that RA can cooperate with growth factors in the activation of XlHbox 6 and that activation by RA is dependent upon exposure of the animal caps to bFGF or XTC-MIF.

\section{Discussion}

We have shown that the XlHbox 1 homeo box gene, which is expressed in an anterior region of the embryo, is preferentially activated by XTC-MIF. Conversely, the posteriorly expressed genes $\mathrm{XlHbox} 6$ (this study) and Xhox 3 (Ruiz i Altaba and Melton 1989b) are induced strongly by bFGF and poorly by XTC-MIF. A direct role in the specification of A-P axis has been proposed both for Xhox 3 (Ruiz i Altaba and Melton 1989a) and XlHbox 1 (Wright et al. 1989). Therefore, the differential activation of homeo box genes by growth factors could play an important role in the establishment of the body axis. Furthermore, ectoderm treated with XTC-MIF can act as Spemann's organizer, leading to the induction of head structures (Cooke et al. 1987; Ruiz i Altaba and Melton 1989b|, while animal caps treated with bFGF induce tail structures (Ruiz i Altaba and Melton 1989b). Our results are consistent with the view (Ruiz i Altaba and Melton 1989b) that peptide growth factors could, directly or indirectly, provide postitional information along the A-P axis of the body.

The results reported here for XlHbox 6 suggest that RA can cooperate with growth factors in providing positional information in Xenopus embryos. Interestingly, the action of growth factors is required for that of RA in this regulatory pathway. RA was able to stimulate strongly XlHbox 6 mRNA accumulation at a concentration of $5 \times 10^{-7} \mathrm{M}$ (Fig. 7) in animal caps supplemented with bFGF. This is consistent with the concentrations known to be required to cause teratogenic effects in Xenopus embryos (Durston et al. 1989; Sive et al. 1990). In our hands, a 30-min pulse of RA at the early gastrula stage causes malformations in only $2 \%$ of the embryos at a concentration of $1 \times 10^{-7} \mathrm{M}$. However, when $5 \times 10^{-7} \mathrm{M}$ RA is administered, at least $55 \%$ of the embryos have truncations of head structures (K.W.Y. Cho, E.A. Morita, and E.M. De Robertis, unpubl.). The endogenous concentration of RA in early Xenopus embryos has been shown to be $1.5 \times 10^{-7} \mathrm{M}$ (Durston et al. 1989),

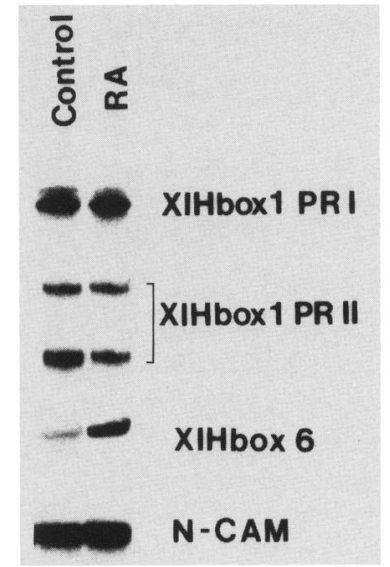

Figure 6. Effect of RA on Xenopus gene expression. RNase protection analysis of homeo box genes and N-CAM gene expression in whole Xenopus embryos after $10^{-6} \mathrm{M}$ RA treatment is shown. Early gastrula embryos were incubated in $10^{-6} \mathrm{M} R A$ for $30 \mathrm{~min}$, washed, and grown to stage 30 . RNA was prepared and amounts of RNA equivalent to embryos were analyzed by RNase protection assays. Note that XlHbox 6 expression is increased by RA (sixfold), while that of XlHbox 1 and N-CAM is unchanged. 
suggesting that even a shallow gradient of RA could differentially activate homeo box genes. Whether the concentrations of bFGF used in this study (either 50 or 200 $\mathrm{ng} / \mathrm{ml}$ ) are in the physiological range is less clear. These concentrations, however, were chosen because they are identical to those shown by Ruiz i Altaba and Melton (1989b) to confer axis-forming activity to transplanted animal cap cells. Because we measured steady-state levels of XlHbox 6 mRNA in all of our experiments, we cannot distinguish whether RA acts at the transcriptional or post-transcriptional level (e.g., on message stability).

The Xenopus animal cap system developed by Nieuwkoop (1969) is very useful because the many inductive interactions that presumably occur in embryos can be tested one at a time. Using this procedure, it was possible to show that growth factors are required for the activation of a homeo box gene by RA. The Xenopus egg contains growth factor molecules of the bFGF (Kimelman and Kirschner 1987; Slack and Isaacs 1989) and of the TGF- $\beta$ type (Weeks and Melton 1987), and presumably others. In addition, they stockpile mRNA for at least four RA-responsive nuclear receptors (B. Blumberg and E. De Robertis, unpubl.). In conclusion, it seems that in the vertebrate embryo, growth factors and RA may cooperate to provide at least some of the signals that lead to differential activation of genes specifying the A-P axis. The results suggest that RA strongly potentiates the effects of peptide growth factors on mesoderm induction.

\section{Materials and methods}

Embryo manipulation

Xenopus laevis eggs laid in high-salt-modified Barth solution

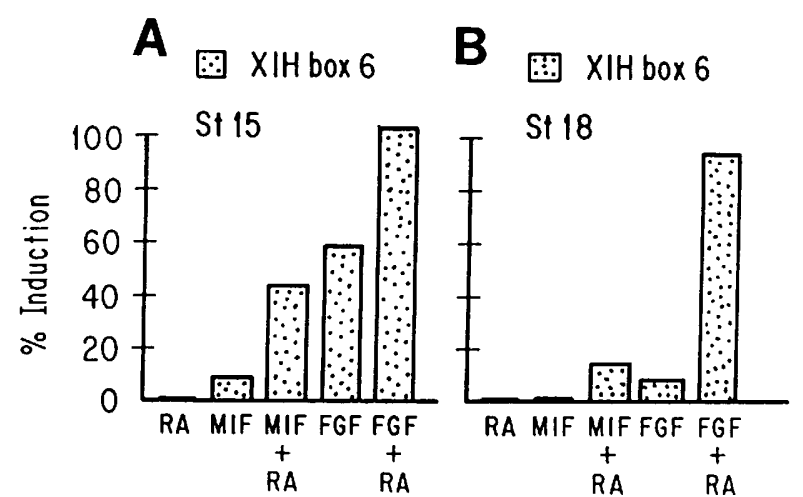

Figure 7. Histograms showing the induction of XlHbox 6 mRNA by growth factors with and without addition of RA. The results shown here are for stage $15(A)$ and $18(B)$ neurulae. In stage 15 equivalent animal cap explants, the induction of $X l H b o x$ mRNA increases two- to fourfold when animal caps were treated both by growth factor and RA. In stage 18 equivalent animal caps, the induction of XlHbox 6 mRNA by RA is 10 - to 20 -fold higher than with growth factor alone. A $100 \%$ induction in these histograms corresponds to the amount of $X 1 H b o x 6$ transcripts in stage 13 animal cap treated with high bFGF in Fig. 5. RA was used at $10^{-5} \mathbf{M}$; similar results were observed with RA at $10^{-6} \mathrm{M}$ (Fig. 8).

\section{XIH box 6}

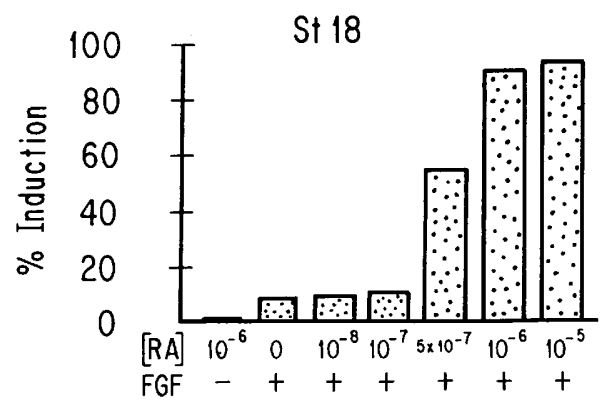

Figure 8. Response of XlHbox 6 transcript to various concentrations of RA in the presence of bFGF $(200 \mathrm{ng} / \mathrm{ml})$. Induction is maximal at $10^{-6} \mathrm{M} \mathrm{RA}$, and significant levels of XlHbox 6 lover half-maximal stimulation) induction were detectable at $5 \times 10^{-7} \mathrm{M}$ RA. Note that RA alone does not induce XlHbox 6 mRNA, but that it greatly potentiates the effect of growth factors. Thirty animal caps were used for each experimental point in this experiment. As in the rest of this study, RNAs were normalized with respect to the amount of elongation factor $1 \alpha$ present in each sample.

(Laskey et al. 1977) were fertilized in vitro. They were dejellied using $2 \%$ cysteine, washed, and transferred to $0.1 \times$ MBS 18.8 $\mathrm{mM} \mathrm{NaCl}, 0.1 \mathrm{mM} \mathrm{KCl}, 0.24 \mathrm{~mm} \mathrm{NaHCO}, 0.082 \mathrm{~mm}$ $\mathrm{MgSO}_{4} \cdot 7 \mathrm{H}_{2} \mathrm{O}, 0.033 \mathrm{mM} \mathrm{Ca}\left(\mathrm{NO}_{3}\right)_{3} \mathrm{H}_{2} \mathrm{O}, 0.041 \mathrm{~mm} \mathrm{CaCl}$, $6 \mathrm{H}_{2} \mathrm{O}, 1 \mathrm{~mm}$ HEPES at $\left.\mathrm{pH} 7.6\right)$ in petri dishes with a $1 \%$ agarose bottom. The embryos were staged according to Nieuwkoop and Faber (1967).

Stage 8 embryos were dechorionated manually, animal and vegetal fragments were dissected in an agar dish containing $1 \times$ Barth, and the dissected embryos were allowed to stand for 15 min to remove loosely attached cells. The dissected explants were then either used to make A/V conjugates /Gurdon et al. 1985 or transferred into growth factor-containing medium and incubated at $18-22^{\circ} \mathrm{C}$. Growth factors were diluted in $1 \times$ MMR [100 mM NaCl, $2 \mathrm{mM} \mathrm{KCl}, 1 \mathrm{mM} \mathrm{MgSO} 4,2 \mathrm{mM} \mathrm{CaCl}_{2}, 5$ $\mathrm{mM}$ HEPES (pH 7.8), and 0.1 mM EDTA; Kimelman and Kirschner 1987]. RNA was isolated when sibling embryos reached the appropriate stages. Whenever necessary, appropriately diluted RA was mixed with growth factors, and animal caps were continuously incubated in medium containing both growth factors and RA. All trans-RA (Sigma) was dissolved in dimethyl sulfoxide (DMSO) at $2 \times 10^{-2} \mathrm{M}$ and stored at $-20^{\circ} \mathrm{C}$. Dilutions of RA were made immediately prior to use using vigorous stirring with a magnetic bar; final concentration of DMSO was $<0.05 \%$. Control embryos were incubated in saline solution containing an equivalent amount of DMSO.

\section{Growth factors}

XTC-MIF conditioned medium was a kind gift of Dr. F. Rosa (National Institutes of Health) and bFGF growth factor was purchased from R\&D Systems, Inc.

The concentrations of growth factors used were as follows: high XTC-MIF, 1: 4 dilution of the XTC-MIF stock medium; low XTC-MIF, 1: 16 dilution of the stock XTC-MIF; high bFGF, $200 \mathrm{ng} / \mathrm{ml}$; low bFGF, $50 \mathrm{ng} / \mathrm{ml}$. XTC-MIF conditioned medium was heated at $95^{\circ} \mathrm{C}$ for $5 \mathrm{~min}$ prior to use to activate the growth factor (Smith 1987) and diluted in MMR medium.

\section{RNA extraction and RNase protection assays}

Animal cap explants were homogenized in a medium con- 
taining $40 \mathrm{~mm}$ Tris- $\mathrm{HCl}$ (pH 7.5), 4 mM EDTA, 1.7\% SDS, 209 $\mathrm{mM} \mathrm{NaCl}$, and $2 \mathrm{mg} / \mathrm{ml}$ proteinase $\mathrm{K}$, incubated at $37^{\circ} \mathrm{C}$ for 10 min, and extracted with phenol-chloroform. An equal volume of $5 \mathrm{M} \mathrm{LiCl}$ was then added to the aqueous phase to precipitate RNA selectively.

RNase protection assays were carried out according to the procedure of Melton et al. (1984), with minor modifications described by Cho et al. (1988). RNA probes were gel-purified from urea-polyacrylamide gels and hybridized overnight at $65^{\circ} \mathrm{C}$ with total RNA equivalent to $20-30$ animal caps in a solution containing $50 \%$ formamide, $40 \mathrm{~mm}$ PIPES (pH 6.7), $400 \mathrm{~mm}$ $\mathrm{NaCl}$, and $1 \mathrm{~mm}$ EDTA. The mixture was digested with RNase $\mathrm{A}$ and $\mathrm{T} 1$ for $10 \mathrm{~min}$ at room temperature, proteinase $\mathrm{K}$-digested, ethanol-precipitated, and subjected to gel electrophoresis.

Probes used for RNase protection assays were as follows. Probes A and B were described previously by Cho et al. (1988) and specifically detect XlHbox 1 PR I and PR II transcription, respectively (see Fig. 1B). Probe $C$ is a clone of XlHbox 6 cDNA (pGls) in a pGEM vector (Promega Corporation) cut with SmaI and transcribed by T3 RNA polymerase to detect XlHbox 6 transcription (see Fig. 1C). The Xenopus N-CAM probe, pNiP, was digested with HindIII and transcribed by SP6 polymerase (Kintner and Melton 1987). The elongation factor probe, pG1EF, was cut with HindIII and transcribed by T7 RNA polymerase to make an antisense probe (Krieg et al. 1989). A Xenopus cytoskeletal actin (Gurdon et al. 1985) was subcloned from a subclone of M13 construct B9.118 (gift of J.B. Gurdon) in Phagescript (Stratagene), and an antisense probe was synthesized by T7 RNA polymerase.

\section{Acknowledgments}

We are grateful to F. Rosa for the XTC-MIF conditioned medium, to T. Mohun and J. Gurdon for the actin probe, to C. Kintner and D. Melton for the N-CAM probe, and to P. Krieg and D. Melton for elongation factor $1 \alpha$ probe. We thank C.V.E. Wright, B. Blumberg, and L. Zipursky for a critical reading of the manuscript. This work was funded by grant HD 21502-05 from the National Institutes of Health (NIH). K.W.Y.C. was a trainee of the UCLA Human Genetics Intercampus Training Program, which is supported by NIH postdoctoral training grant GM 08243.

The publication costs of this article were defrayed in part by payment of page charges. This article must therefore be hereby marked "advertisement" in accordance with 18 USC section 1734 solely to indicate this fact.

\section{References}

Bogarad, L.D., M.F. Utset, A. Awgulewitsch, T. Miki, C.P. Hart, and F. Ruddle. 1989. The developmental expression pattern of a new murine homeo box gene: Hox-2.5. Dev. Biol. 133: $537-549$.

Cho, K.W.Y., J. Goetz, C.V.E. Wright, A. Fritz, J. Hardwicke, and E.M. De Robertis. 1988. Differential utilization of the same reading frame in a Xenopus homeobox gene encodes two related proteins sharing the same DNA-binding specificity. $E M B O$ I. 7: 2139-2149.

Cooke, J., J.C. Smith, E.J. Smith, and M. Yaqoob. 1987. The organization of mesodermal pattern in Xenopus laevis: Experiments using a Xenopus mesoderming-inducing factor. Development 101: 893-908.

De Robertis, E.M., G. Oliver, and C.V.E. Wright. Determination of axial polarity in the vertebrate embryo: Homeodomain proteins and homeogenetic induction. Cell 57: 189-191.
1990. Homeobox genes and the vertebrate body plan. Sci. Am. 363: 46-52.

Dolle, P. and D. Duboule. 1989. The structural and functional organization of the murine HOX gene family resembles that of Drosophila homeotic genes. EMBO J. 8: 1497-1505.

Durston, A.J., J.P. Timmermans, W.J. Hage, H.F. Hendriks, N.J. De vries, M. Heideveld, and P.D. Nieuwkoop. 1989. Retinoic acid causes an anteroposterior transformation in the developing central nervous system. Nature 340: 140-144.

Fritz, A.F., K.W.Y. Cho, C.V.E. Wright, B. Jegalian, and E.M. De Robertis. 1989. Duplicated homeobox genes in Xenopus. Dev. Biol. 131: 584-588.

Graham, A., N. Papalopulu, J. Lorimer, J.H. McVey, E.G. Tuddenham, and R. Krumlauf. 1989. The murine and Drosophila homeobox gene complexes have common features of organization and expression. Cell 57: 367-378.

Green, J.B.A., G. Howes, K. Symes, J. Cooke, and J.C. Smith. 1990. The biological effects of XTC-MIF: Quantitative comparison with Xenopus bFGF. Development 108: 173-183.

Gurdon, J.B., S. Fairman, T.J. Mohun, and S. Brennan. 1985. Activation of muscle-specific actin genes in Xenopus development by an induction between animal and vegetal cells of a blastula. Cell 41: 913-922.

Kessel, M., R. Balling, and P. Gruss. 1990. Variation of cervical vertebrae after expression of a Hox-1.1 transgene in mice. Cell 61: 301-308.

Kimelman, D. and M. Kirschner. 1987. Synergistic induction of mesoderm by FGF and TGF-beta and the identification of an mRNA coding for FGF in the early Xenopus embryo. Cell 51: 869-877.

Kintner, C. and D.A. Melton. 1987. Expression of Xenopus N-CAM RNA in ectoderm is an early response to neural induction. Development 99: 311-325.

Krieg, P.A., S.M. Varnum, W.M. Wormington, and D.A. Melton. 1989. The mRNA encoding elongation factor $1-\alpha$ $(E F-1 \alpha)$ is a major transcript at the midblastula transition in Xenopus. Dev. Biol. 133: 93-100.

Laskey, R.A., A.D. Mills, and N.R. Morris. 1977. Assembly of SV40 chromatin in cell-free system from Xenopus eggs. Cell 10: $237-243$.

Mavilio, F., A. Simeone, E. Boncinelli, and P.W. Andrews. 1988. Activation of four homeobox gene clusters in human embryonal carcinoma cells induced to differentiate by retinoic acid. Differentiation 37: 73-79.

Melton, D.A., P.A. Krieg, M.R. Rebagliati, T. Maniatis, K. Zinn, and M. Green. 1984. Efficient in vitro synthesis of biologically active RNA and RNA hybridization probes from plasmids containing a bacteriophage SP6 promoter. Nucleic Acids Res. 12: 7035-7056.

Nieuwkoop, P.D. 1969. The formation of the mesoderm in urodelean amphibians. I. Induction by the endoderm. Roux's Arch. Entw. Mech. Org. 162: 341-373.

Nieuwkoop, P.O. and J. Faber. 1967. Normal table of Xenopus laevis (Daudin). North Holland, Amsterdam.

Rosa, F. 1989. Mix.1, a homeobox mRNA inducible by mesoderm inducers is expressed mostly in the presumptive endoderm cells of Xenopus embryos. Cell 57: 965-974.

Ruiz i Altaba, A. and D.A. Melton. 1989a. Involvement of the Xenopus homeobox gene Xhox 3 in pattern formation along the antero-posterior axis. Cell 57: 317-326.

Ruiz i Altaba, A. and D.A. Melton. 1989b. Interaction between peptide growth factors and homeobox genes in the establishment of antero-posterior polarity in frog embryos. $\mathrm{Na}$ ture 341: 33-38.

Sharpe, C.R., A.F. Fritz, E.M. De Robertis, and J.B. Gurdon. 1987. A homeobox-containing marker of posterior neural 
Cho and De Robertis

differentiation shows the importance of predetermination in neural induction. Cell 50: 749-758.

Sive, H.L., B.W. Draper, R.M. Harland, and H. Weintraub. 1990. Identification of retinoic acid sensitive period during primary axis formation in Xenopus laevis. Genes Dev. 4: 932942.

Slack, J.M.W. and H.V. Isaacs. 1989. Presence of basic fibroblast growth factor in the early Xenopus embryo. Development 105: $147-153$.

Slack, J.M.W., B.G. Darlington, J.K. Heath, and S.F. Godsave. 1987. Mesoderm induction in early Xenopus embryos by heparin-binding growth factors. Nature 326: 197-200.

Smith, J.C. 1987. A mesoderm-inducing factor is produced by a Xenopus cell line. Development 99: 3-14.

Smith, J.C., M. Yaqoob, and K. Symes. 1988. Purification, partial characterization and biological properties of the XTC mesoderm-inducing factor. Development 103: 591-600.

Smith, J.C., B.M.J. Price, K. Van Nimmen, and D. Huylebroeck. 1990. Identification of a potent Xenopus mesoderm-inducing factor as a homologue of activin A. Nature 345: 729-731.

Spemann, H. 1938. Embryonic development and induction. Yale University Press, New Haven.

Thaller, C. and G. Eichele. 1987. Identification and spatial distribution of retinoids in the developing chick limb bud. $\mathrm{Na}$ ture 327: 625-628.

Tickle, C., B. Alberts, L. Wolpert, and J. Lee. 1982. Local application of retinoic acid to the limb bud mimics the action of the polarizing region. Nature 296: $564-566$.

Weeks, D.L. and D.A. Melton. 1987. A maternal mRNA localized to the vegetal hemisphere in Xenopus eggs codes for a growth factor related to TGF-beta. Cell 51:861-867.

Wright, C.V.E., K.W.Y. Cho, J. Hardwicke, R.H. Collins, and E.M. De Robertis. 1989. Interference with function of a homeobox gene in Xenopus embryos produces malformations of the anterior spinal cord. Cell 59: 81-93.

Wright, C.V.E., E.A. Morita, D.J. Wilkin, and E.M. DeRobertis. 1990. The Xenopus XlHbox 6 homeo protein, a marker of posterior neural induction, is expressed in proliferating neurons. Development 109: 225-234. 


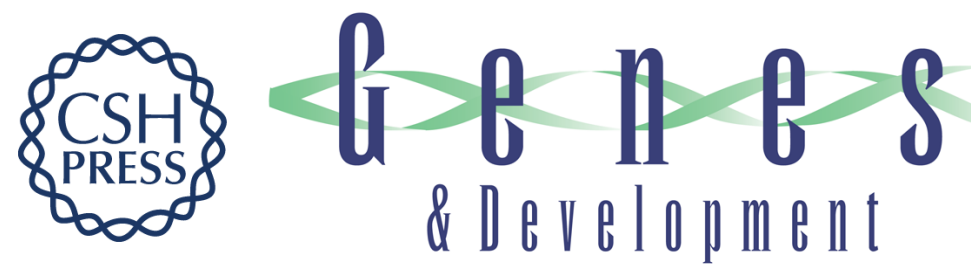

\section{Differential activation of Xenopus homeo box genes by mesoderm-inducing growth factors and retinoic acid.}

K W Cho and E M De Robertis

Genes Dev. 1990, 4:

Access the most recent version at doi:10.1101/gad.4.11.1910

References This article cites 33 articles, 8 of which can be accessed free at:

http://genesdev.cshlp.org/content/4/11/1910.full.html\#ref-list-1

License

Email Alerting

Service

Receive free email alerts when new articles cite this article - sign up in the box at the top right corner of the article or click here.

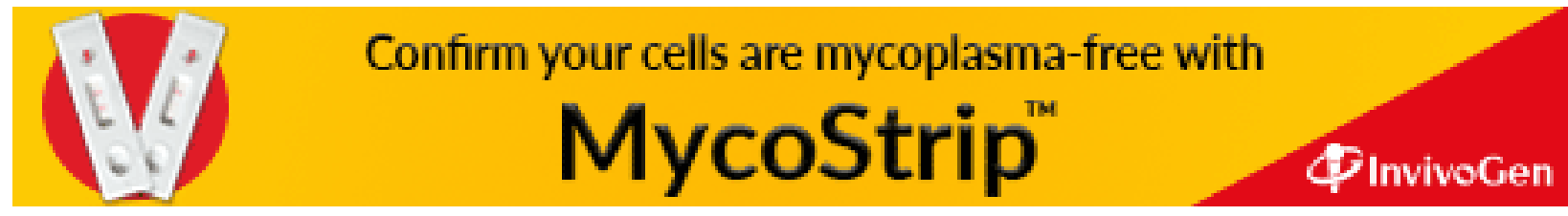

